\title{
Kyphoplasty: Chances and limits
}

\author{
Christian W. Mueller, Ulrich Berlemann \\ Orthopaedic Trauma Department, Hannover Medical School (MHH), Carl-Neuberg-Str.1, D-30625 Hannover, Germany
}

\begin{abstract}
Kyphoplasty provides a minimal-invasive surgical technique for the cement augmentation of vertebral bodies following osteoprotic compression fractures or malignant processes. Kyphoplasty has been developed as an advancement of vertebroplasty. Both procedures feature high-success rates in terms of reliable and lasting reduction of pain. Advantages of kyphoplasty over vertebroplasty are to be seen in the possibility of deformity correction as well as in a decreased risk of cement leakage, which represents the most important source for clinical complications. Long-term experiences with the effect of cementing vertebral bodies are sparse. Thus indications and possibilities have to be judged realistically. Conditions, which have to be considered before performing kyphoplasty or vertebroplasty include age of the patient, age of the fracture, degree of deformation and additional degenerative changes of the spine. This article summarizes the present research and literature as well as indications and contraindications and is thought to provide guidelines for the aforementioned decision-making processes.
\end{abstract}

Key words: Kyphoplasty; osteoporosis; spine; vertebroplasty

Percutaneous augmentation techniques of the spine have enhanced options for the treatment of osteoporotic vertebral body fractures in elderly people to a great part. In addition to vertebroplasty, the injection of polymethyl methacrylate (PMMA) into a fractured vertebral body without reduction - kyphoplasty features the possibility of at least partial height restoration of a fractured vertebral body. While these techniques are rapidly adopted as technically feasible procedures, long-term experience is still sparse. Thus, indications have to be strict and possibilities have to be pondered cautiously in order to avoid complications on the one hand and unrealizable expectations on the other hand.
The primary goal of these techniques has to be to achieve a reliable and lasting reduction of pain by using a reasonably safe procedure, resulting in an increased mobility and quality of life.

This article conveys the common grounds as well as the limits of this relatively new technique, bases on the current literature and our own experience. Precise technical details of the procedure have been described elsewhere and are not repeated in this article. ${ }^{[1]}$

\section{Vertebroplasty}

Since 1987, vertebroplasties are used in the treatment of osteoporotic vertebral body compression fractures (VBCF) as well as for augmentation of osteolytic metastatic processes of the vertebral body or multiple myeloma. Guided by fluoroscopy, bone biopsy cannulas are introduced into the vertebral body and contrast-enhanced PMMA is injected into the vertebral body via these cannulas. Usually, this procedure is performed under local anaesthesia. Vertebroplasty results in a rapid and significant reduction of pain in $80-90 \%$ of all treated patients. These results are reported both for osteoporotic VBCF and osteolytic processes of the vertebral body. ${ }^{[2-5]}$ Little data has been published about long-term results, but at least in osteoporotic VBCF pain reduction seems to last even $4-5$ years after the procedure. ${ }^{[6,7]}$

Following the rapid spreading of this technique and its increasing number of applications, meanwhile the risk of extravertebral cement leakage has become clear as well. Especially leakage into epidural veins may result in severe complications, including fatal pulmonary embolisms. ${ }^{[8,9]}$ Since the cement has to be injected at a high pressure - even if the pressure coming out of the needle is lower than inside the needle - with relatively low viscosity, the risk of extrusion is even more immanent in vertebral fractures which affect the posterior wall (burst fractures) or osteolytic defects. Consequently, intra- and postoperative X-rays show cement leakage in up to $65 \%$ of all treated vertebral bodies. ${ }^{[10]}$ Accurate CT scans show extrusion in almost all procedures. ${ }^{[11]}$ A recent study from Choe et al. revealed pulmonary embolism of cement in $4.6 \%$ of patients after percutaneous vertebroplasty or kyphoplasty. 
Pulmonary embolism correlated with paravertebral venous cement leakage but not with type of procedure performed - kyphoplasty vs vertebroplasty. ${ }^{[12]}$ In order to prevent cement extrusion, Groen et al. suggested increasing the vertebral venous pressure during surgery. This could be achieved by operating the patient in the prone position and by raising intrathoracic venous pressure with the aid of the anaesthesiologist during intravertebral instrumentation and cement injection. ${ }^{[13]}$ Beside cement emboli, cement injection into the vertebral body can result in fat embolism. In animal experiments, this resulted in arterial hypotension. ${ }^{[14]}$ Whether these findings are clinically significant has not been proven yet.

Another issue is the reaction of adjacent levels after augmentation of a vertebra. Over a follow-up period of 4 years Grados et al. found additional fractures in $52 \%$ of their patients. ${ }^{[6]}$ Biomechanical investigations have confirmed clinical experience of an elevated risk of new fractures in the vicinity of augmented vertebrae. ${ }^{[15]}$ One possible reason could be the different rigidities in augmented and nonaugmented vertebrae; another could be additional stress due to the kyphosis which is not addressed by vertebroplasty. Recent studies investigate the effect of multiple and prophylactic augmentations. ${ }^{[16]}$

\section{Kyphoplasty}

The primary goal of kyphoplasty is the reduction of pain caused by VBCF. In addition, kyphoplasty aims for restoration of the fractured vertebral body and correction of the local kyphosis, which follows VBCF. Restoration is achieved by inflation of an expandable balloon tamp which is introduced into the vertebral body via a transpedicular approach prior to the application of bone cement. By expanding the balloon, the endplate is lifted and a cavity is formed which persists after removal of the balloon tamp. Afterwards, the cavity is filled up with bone cement to maintain reduction. In comparison to vertebroplasty the cement used in kyphoplasty features higher viscosity and the pressure needed for application is considerably less. In addition, the volume needed for augmentation is known from the balloon expanding procedure. Thus, the risk of cement leakage can be reduced significantly. ${ }^{[17]}$ Also, the use of other bone substitution materials of higher viscosity, such as calcium phosphate, is facilitated. ${ }^{[18]}$ According to clinical experience, average restoration of $33-50 \%$ of height of the vertebral body is feasible. The possible amount of restoration seems to decline with the age of the fracture. ${ }^{[19-21]}$ Nevertheless, in a study of Kasperk et al., who treated patients suffering from chronically painful VBCF for more than 12 months, kyphoplasty resulted in an increase of vertebral height of $12 \% 6$ months after the intervention, whereas vertebral height decreased by $8 \%$ in the control group. ${ }^{[22]}$ In acute fractures, even positioning of the patient in prone position with the spine in hyperextension on the operating table might lead to a certain degree of height restoration. ${ }^{[23]}$ The location of the treated level seems to influence the extent of augmentation as well, since kyphoplasties of the lumbar spine are more likely to achieve a significant height restoration than those of the thoracic spine. In the authors' own patients and other reports no significant loss of height restoration was seen within 1 year after the procedure. ${ }^{[19,24]}$ Although the association between pain and decrease of mobility on the one hand and extent of spine deformity on the other is well known, it remains unclear whether patients benefit from height restoration of the fractured vertebral body on the long run. ${ }^{[19,25]}$ As with vertebroplasty, there is an increased risk of higher rate of subsequent fractures after kyphoplasty compared with natural history data for untreated fractures. In a study of Fribourg et al., most of these occurred at an adjacent level within 2 months of the index procedure. After this 2 -month period, there were only occasional subsequent fractures, which occurred at remote levels. ${ }^{[26]}$ Doubtlessly, clinical studies are needed to elucidate these associations, but prospective, randomized studies comparing vertebroplasty and kyphoplasty in terms of long-term results regarding pain and mobility are still missing.

\section{Indications}

\section{Osteoporotic vertebral compression fractures}

The osteoporotic compression fracture of the thoracolumbar spine is the main indication to perform a kyphoplasty or a vertebroplasty. Preoperatively, the main challenge is the sound identification of a symptomatic VBCF. It is essential to discriminate an acute event with sudden onset of pain, usually without adequate trauma and plain X-rays showing radiological signs of an acute fracture, from chronic conditions of painful disorders of the spine.

Acute fractures: CT scans are only needed in cases of high deformity and in burst fractures, in which protrusion of fragments into the spinal canal has to be excluded. On the other hand, MRT scans may give valuable additional information in regard to the age of a deformity of a vertebral body with acute fractures usually showing a significant bone oedema. The decision when to perform kyphoplasty can be made upon deformity of the vertebral body and extent of disability. It is well known that a considerable portion of VBCF causes only moderate pain and heals within a few weeks with moderate deformity. Beside the radiological extent of the deformity the ability of mobilization is another valuable clinical parameter. If the patient can be mobilized and discomfort is tolerable, conservative treatment should be considered at first hand. This treatment should comprise adequate analgesia as well as guided physiotherapy. It is mandatory to re-evaluate these patients on a regular basis (Figure 1). In benign courses, pain decreases significantly within 4-6 weeks and a further sintering of the broken vertebra does not occur. In this case, functional treatment should be continued. If the patient still complains of significant pain or X-rays show a further collapsing of the vertebral body, augmentation techniques can still be performed successfully, sometimes even as 1-day surgery (Figures 2 and 3). This concept allows avoiding overtreatment of benign courses on the one hand, on the other unfavourable courses are still recognized and addressed in time.

Chronic processes: Finding the cause of chronic pain of the 


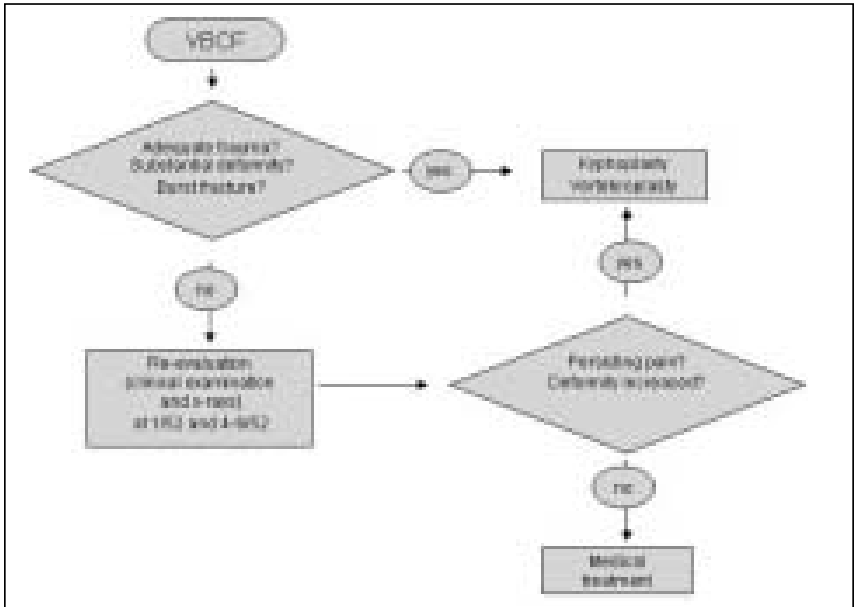

Figure 1: Algorithm for the treatment of osteoporotic vertebral body compression fractures (VBCF). Timely re-evaluation is mandatory to avoid unfavourable courses

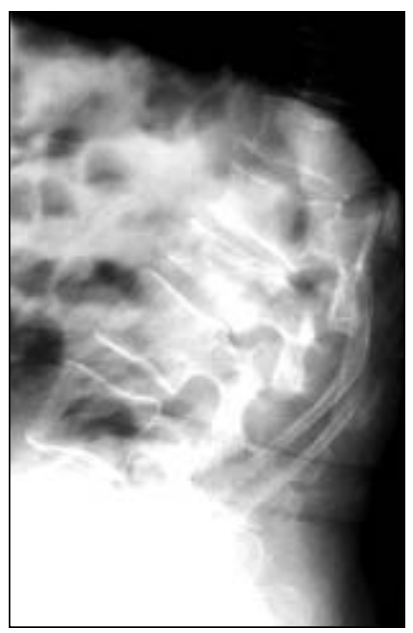

Figure 2: Vertebral body compression fractures (VBCF) at L1 in a 56year-old female, who fell while being on a boat-trip. First presentation in our emergency room 3 weeks after the incident, complained of persisting pain after mobilization. Thoracolumbar spine at admission

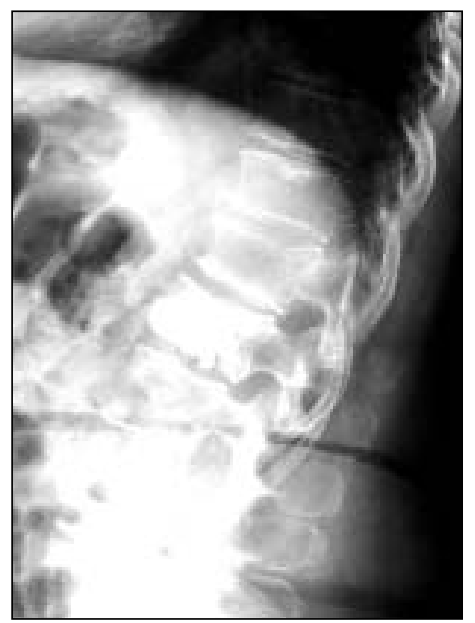

Figure 3: Day-surgery kyphoplasty L1 was performed resulting in reduction of the local kyphosis of $11^{\circ}$ and reduction of pain measured by visual analog scale (VAS) from seven preoperatively to

three immediately postoperatively and to one 6 week thereafter. Thoracolumbar spine postoperatively spine is usually much more difficult. Quite often combined pathologies of osteoporotic changes of unknown age, spondylosis, spondylarthrosis, degenerative spondylisthesis and stenosis of the spinal canal are found. In our experience, theses cases regularly require - in addition to a thorough case history - magnetic resonance imaging (MR scans). MR scans, especially fat suppressed STIR sequences, facilitate the selection of eligible deformities by identification of bone oedema of the vertebral body. ${ }^{[27]}$ Like skeletal scintigraphy, this signal enhancement correlates with 'ongoing activity' within the vertebral body which regularly accounts for painfulness. Furthermore, plain X-rays in flexion and extension of the spine may indicate other conditions like instability or pseudarthrosis following fractures of the vertebral body. In our own patients, we occasionally perform diagnostic facet joint injections to identify the painful level. In patients with relevant kyphosis, the facetjoint is at a posture of hyper-flexion. If all tests indicate a painful vertebral fracture, augmentation is indicated even in cases of longer history.

Malign processes: When Galibert and Deramond first described this technique, vertebroplasty was performed to stabilize vertebrae with haemangioma. ${ }^{[28]}$ Not until the following years, vertebroplasty was used in the treatment of $\mathrm{VBCF}$ and nowadays the main indication for both kyphoplasty and vertebroplasty actually are vertebral compression fractures. As with $\mathrm{VBCF}$, in the treatment of malignant processes the reduction of pain is the main purpose of augmentation techniques, which exceptionally even has been used in the cervical spine. ${ }^{[29]}$ Larger case series usually comprise metastases of various primary tumours as well as multiple myeloma. ${ }^{[4,30,31]}$ Especially in the treatment of vertebrae with metastases augmentation has to be regarded as palliative, but still quite worthwhile in terms of effective pain control. ${ }^{[32]}$ However, the role of palliative augmentation as compared to radiotherapy has not been well defined yet.

Kyphoplasty vs vertebroplasty: Several clinical studies have shown significant reduction of pain in 70-90\% of all patients undergoing vertebroplasty and in $67-100 \%$ of all patients undergoing kyphoplasty. ${ }^{[5,33]}$ This effect seems to be similar in both vertebroplasty and kyphoplasty. Nevertheless, randomized controlled trials comparing vertebroplasty against kyphoplasty are still missing. Taken from the data published so far and personal experience the risk of extrusion of bone cement is smaller in kyphoplasty than in vertebroplasty. ${ }^{[17]}$ Biomechanical and pathophysiological considerations suggest that height restoration of the deformed vertebral body should be desirable. However, until now the effectiveness of height restoration has not been proven. On the downside, material costs are much higher in kyphoplasty. In order to reduce cannulation risk, operative time, radiation exposure and cost, it has been suggested to perform unipedicular rather than bipedicular kyphoplasty. In a cadaver study by Steinmann et al., both approaches were comparable in respect of mean strength, average stiffness and height restoration. ${ }^{[34]}$ Recently, Heini et al. proposed the so-called lordoplasty as an alternative technique for kyphosis correction: Adjacent vertebrae are reinforced first and cannulas are introduced. Reduction of 
the kyphotic vertebra is then performed by using the cannulas as a lever. ${ }^{[23]}$

From our experience, the following points speak in favour of performing a kyphoplasty rather than a vertebroplasty:

- Kyphosis in a deformed vertebral body of more than $10^{\circ}$ or height loss of more than a third: in these cases realignment of the spine should be aspired.

- Serious deformity of the vertebral body with affection of the posterior wall: realignment is required at the lowest possible risk of cement extrusion.

- Deformities, which are less than 8-week old: (partial) height restoration is probably feasible in these VBCF.

- Comparatively young and active patients: a long-term benefit of height restoration is expected in these patients.

\section{Contraindications}

The most important contraindication for percutaneous augmentation is the lack of coherence between the patient's complaints and the radiological lesion. This coherence is absolutely mandatory. Although osteoporosis is found in the vast majority of patients, complaints might not be attributable to a distinct level and might well be due to other reasons like degenerative changes as mentioned above. Further absolute contraindications are infectious processes of the spine. Especially spondylodiscitis can mimic vertebral compression fracture in plain X-rays (Figures 4 and 5). Patient-related contraindications include untreatable coagulopathies and allergies against PMMA or contrast medium. Technical problems contain presentability of the index segment by a c-arm image intensifier. Multiple previous surgeries or massive adiposity may impede proper identification of anatomical landmarks for the positioning of cannulas and balloon tamps. Even presentability of the vertebral body can be too poor to allow a visualization of the process of filling up the vertebral body with PMMA cement. Thus, a safe procedure can be impossible.

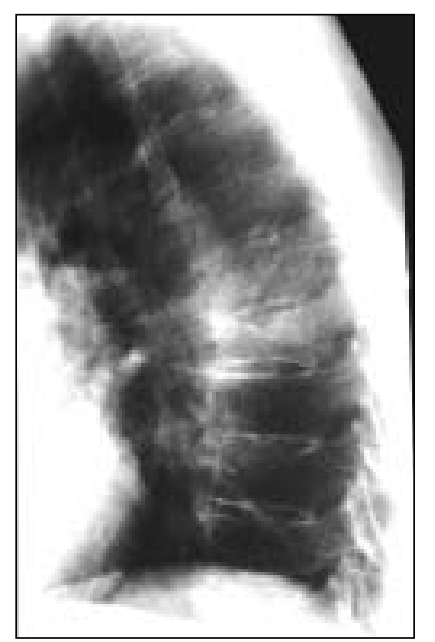

Figure 4: Sixty-two-year-old female presenting with pain of the thoracic spine without any history of trauma. Plain X-rays suggest suspicion of vertebral body compression fractures (VBCF)
Particularly in the upper thoracic and lumbosacral spine radiological visualization often is hampered due to the vicinity of shoulders or pelvis.

\section{Relative indications}

The grey area of relative indications and contraindications include the age limit of patients with deformities of the vertebrae. Results, that have been published so far, are usually derived from elderly patient, with 55-60 years seen as the youngest age for these procedures. The reason is that most of the applicable fractures, i.e. osteoporotic compression fractures, occur in elderly patients. More rarely these fractures are found in younger patients, e.g. following severe secondary osteoporosis due to long-term intake of steroids. In these cases decision has to be made individually. Other eligible fractures are found in patients suffering from ontogenesis imperfecta, which have been treated successfully by applying vertebroplasty. ${ }^{[35]}$ Even incomplete burst, fractures might be eligible for augmentation techniques, especially for kyphoplasty (Figures 6 and 7). In cases of significant destruction of the posterior wall and neural damage, kyphoplasty can be integrated into open surgery with decompression of the spinal canal via interlaminary windowing. ${ }^{[36]}$ Generally, this type of fracture in elderly patients has to be discriminated from radiologically similar lesion in younger patient. In particular, injury to the intervertebral discs is much more important in younger patients and requires adequate considerations in the choice of treatment. A controversial issue is pre-existing or fracture-related neural damage and kyphoplasty. In general, spinal or foraminal stenosis is not apt for kyphoplasty, since these problems cannot be addressed by injection of PMMA cement. In our opinion a symptomatic spinal canal stenosis with significant claudicatio intermittens should be held as a contraindication. On the other hand, a series of lumbar radiculopathies has been described, which had been aggravated by vertebral instability due to VBCF. In these cases, pain was significantly reduced after performing vertebroplasty. ${ }^{[37]}$ Recently,

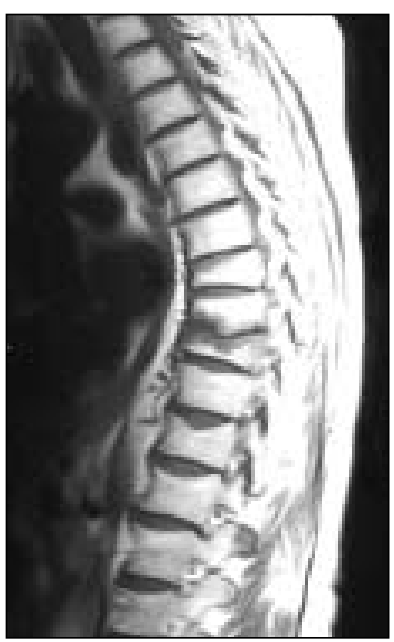

Figure 5: MR scans reveal signs of spondylodiscitis. Under treatment with antibiotics uneventful further course without additional deformity of the vertebral body 


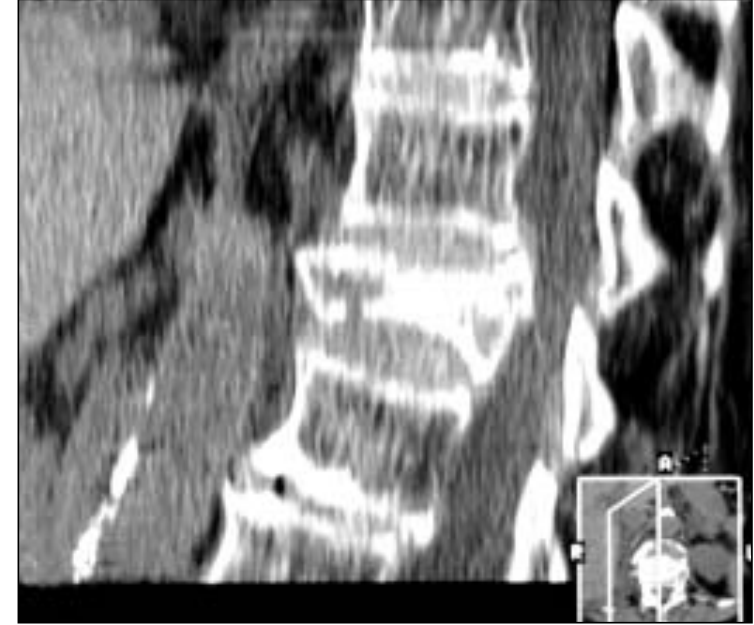

Figure 6: Seventy-eight-year-old female, who fell from a ladder Multiple comorbidities. CT scans show a L1 burst fracture with affection of the posterior wall and narrowing of the spinal canal of approx. $40 \%$. Clinically no signs of neurological deficits

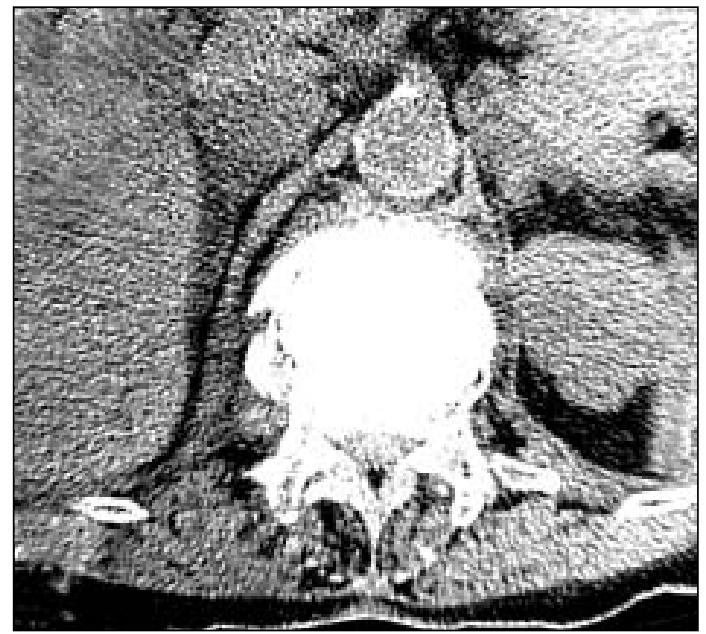

Figure 7: Kyphoplasty was performed resulting in good height restoration and pain reduction from visual analog scale (VAS) eight to two postoperatively. Mobilization was started the day of surgery. Postoperatively no signs of neurological deficits. CT scan shows adequate distribution of bone cement and no extrusion from the vertebral body

Masala et al. published a case report of a patient with a diagnosis of Guillain-Barre syndrome, who was admitted with a severe paraparesis and a fracture at the D12 vertebral body. MR imaging excluded compression of the spinal cord at that level. Kyphoplasty was successfully performed and enabled a prompt start of rehabilative therapy. ${ }^{[38]}$

\section{Discussion}

Osteoporotic vertebral compression fractures account for a great part of spinal morbidity in elderly patients. These aches influence mobility and quality of life and lead to a significantly increased mortality following $\mathrm{VBCF}^{[10,39-41]}$ Due to the rising average age of our population, the incidence of $\mathrm{VBCF}$ will multiply during the next decades. Subsequently, the importance and employment of percutanous augmentation techniques will rise as well. Vertebroplasty and kyphoplasty have impressively proven their capability to reduce pain due to vertebral instability and deformity. Only recently, the first two nonrandomized prospective trials comparing clinical outcome of kyphoplasties versus conservative treatment have been published. Kasperk et al. conducted a study comparing 40 patients undergoing kyphoplasty against 20 patients who were eligible for kyphoplasty but opted for conservative treatment. Beside changes in radiomorphology of the spine, pain visual analog scale (VAS) scores and daily activities [European vertebral osteoporosis study (EVOS) score] were assessed at 3- and 6-month follow ups and compared to baseline scores. (Table 1) summarizes outcome data from this study. VAS scores were significantly better in the kyphoplasty group compared to the control group after 3 and 6 months, while EVOS scores were significantly better in the kyphoplasty group after 6 months, but not after 3 months. ${ }^{[22]}$

A study by Komp et al. who compared 19 patients undergoing kyphoplasty and 17 patients with conservative treatment at 6 week and 6-month follow ups showed similar results. ${ }^{[42]}$ The actual mechanism which leads to the significant reduction of pain after both vertebroplasty and kyphoplasty still is a matter of ongoing discussion. Local cytotoxicity as well as heat from the exothermic polymerization reaction of the PMMA cement have been proposed as possible reasons. ${ }^{[4,44]}$ Yet, pain relief seems to be comparable in kyphoplasties performed by using calciumphospate cement, which hardens almost isothermically. ${ }^{[18]}$ Thus, the prevention of 'micromotion' within the fractured vertebral body, resulting in permanent irritation of intraosseous or periosteal nerves, has been suggestes as the pain-relieving mechanism. ${ }^{[45,46]}$ However, the amount of cement needed to achieve this effect is unknown. In a biomechanical study on cadaveric specimens, Belkoff et al. found $2 \mathrm{ml}$ of cement to be sufficient to restore the strength of the vertebral body, while 4-8 $\mathrm{ml}$ of cement were needed to restore stiffness. ${ }^{\left[{ }^{[3]}\right.}$ A clinical study showed no correlation between the volume of cement injected and pain relief in vertebroplasties of

Table 1: Clinical outcome data from the study by Kasperk et al. $^{[22]}$

\begin{tabular}{|c|c|c|c|c|c|c|c|c|c|}
\hline \multirow[b]{3}{*}{$\begin{array}{l}\text { EVOS } \\
\text { score - } \\
\text { kyphoplasty } \\
\text { group }\end{array}$} & \multicolumn{3}{|c|}{ Baseline } & \multicolumn{3}{|c|}{3 months } & \multicolumn{3}{|c|}{6 months } \\
\hline & Mean & SE & $\bar{N}$ & Mean & SE & $\bar{N}$ & Mean & SE & $N$ \\
\hline & $43.8^{\mathrm{NS}}$ & 2.4 & 40 & $52.7^{\mathrm{NS}}$ & 2.6 & 32 & $54.4^{*}$ & 2.7 & 40 \\
\hline $\begin{array}{l}\text { EVOS score } \\
\text { - control } \\
\text { group }\end{array}$ & 39.8 & 4.5 & 20 & 45.1 & 5.3 & 14 & 43.8 & 4.6 & 20 \\
\hline $\begin{array}{l}\text { VAS score } \\
\text { - kyphoplasty } \\
\text { group }\end{array}$ & $26.2^{\mathrm{NS}}$ & 2.0 & 40 & $42.4^{*}$ & 2.9 & 38 & $44.2^{*}$ & 3.3 & 40 \\
\hline $\begin{array}{l}\text { VAS score } \\
\text { - control } \\
\text { group }\end{array}$ & 33.6 & 4.1 & 20 & 33.9 & 4.6 & 16 & 35.6 & 4.1 & 20 \\
\hline
\end{tabular}


osteolytic processes. ${ }^{[47]}$ Yet, data from class I - i.e. randomized controlled - clinical trials is still missing. Currently the first prospective randomized controlled trial comparing kyphoplasty vs conservative treatment is performed at various centres in Europe and the US. Results from this study will most probably influence the significance of this technique in the future. Doubtlessly, kyphoplasty as compared to vertebroplasty features a decreased risk of cement leakage and the potential of controlled height restoration of compressed vertebral bodies. The downside on the other hand is the expensiveness of this innovative technique. On the other hand, to our experience the length of a hospital stay for conservative treatment after $\mathrm{VBCF}$ can be reduced tremendously by performing kyphoplasty, which usually enables quick mobilization and discharge. However, controlled studies aiming at cost-effectiveness of augmentation techniques as compared to conservative treatment are still missing, too.

Further advancements of these techniques are to be expected regarding to the integration of other materials for augmentation. Particularly, cements made of calcium phosphate are currently used in first clinical applications; ${ }^{[18,48]}$ even, if the knowledge about long-term effects, which the different materials might exert on the vertebral body, is still sparse. Thus, another topic of future research has to be the in-vivo evaluation of these materials in adequate osteoporosis animal models.

Only recently, Ohnsorge et al. showed the option of implementation of computer-assistence into the kyphoplasty procedure. Positioning of the working cannulas was planned and navigated using a fluoroscopic navigation system based on 3DCT data. Thus, accuracy could be increased and radiation exposure reduced at the same time. ${ }^{[49]}$

\section{Conclusion}

Painful osteoporotic vertebral compression fractures can be successfully stabilized at a high-success rate and comparatively little effort by the use of percutaneous augmentation techniques, such as kyphoplasty and vertebroplasty. Their overall complication rate is low, although in singular cases extrusion of cement into the spinal canal or into the epidural veins has resulted in fatal complications. Acute fractures with tolerable pain and only little deformity still justify starting conservative treatment. However, the decision in favour of conservative treatment imposes the need for clinical and radiological follow-up examinations to prevent long and painful courses and severe secondary deformities of the vertebral body. Usually, these deformities can still be successfully corrected, if kyphoplasty is performed within 6-8 weeks. In chronic painful processes, meticulous preoperative examination is needed to discriminate pain caused by a radiologically verifiable vertebral compression fracture from pain of other reasons. It has to be underlined, that medical treatment, i.e. pain medication, e.g. $1 \mathrm{~g}$ of calcium, $1000 \mathrm{IE}$ of vitamin $\mathrm{D}_{3}$ and standard dose of aminophosphonate, should be given to all patients suffering from osteoporotic VBCF, whether they undergo augmentation procedures or not. Future research will concentrate on the evaluation of new materials, that are suitable for augmentation and reliable osteoporosis animal models will be needed to validate these materials in vivo.

\section{References}

1. Berlemann U, Heini PF. Perkutane Zementierungstechniken zur Behandlung osteoporotischer Wirbelkörpersinterungen. Unfallchirurg 2002;105:2-8

2. Barr JD, Barr MS, Lemley TJ, McCann RM. Percutaneous vertebroplasty for pain relief and spinal stabilization. Spine 2000;25: 923-8

3. Evans A.J, Jensen ME, Kip KE, DeNardo A.J, Lawler G.J, Negin GA, et al. Vertebral compression fractures: pain reduction and improvement in functional mobility after percutaneous methacrylate vertebroplasty - retrospective report of 245 cases. Radiology 2003;226: 366-72

4. Fourney DR, Schomer DF, Nader R, Chlan-Fourney J, Suki D, Ahrar K, et al. Percutaneous vertebroplasty and kyphoplasty for painful vertebral body fractures in cancer patients. J Neurosurg 2003;98: 21-30

5. Heini PF, Walchli B, Berlemann U. Percutaneous transpedicular vertebroplasty with PMMA - a prospective study for the treatment of osteoporotic compression fractures. Eur Spine J 2000;9:445-50

6. Grados F, Depriester C, Cayrolle G, Hardy N, Deramond H, Fardellone P. Longterm observations of vertebral osteoporotic fractures treated by percutaneous vertebroplasty. Rheumatology 2000;39:1410-4

7. Perez-Higueras A, Alvarez L, Rossi RE, Quinones D, Al-Assir I. Percutaneous vertebroplasty: long-term clinical and radiological outcome. Neuroradiology $2002 ; 44: 950-4$

8. Chen HL, Wong CS, Ho ST, Chang FL, Hsu CH, Wu CT. A lethal pulmonary embolism during percutaneous vertebroplasty. Anesth Analg 2002;95: 1060-2.

9. Lee B.J, Lee SR, Yoo TY. Paraplegia as a complication of percutaneous vertebroplasty with polymethyl methacrylate - a case report. Spine 2002;27:E419-22

10. Cortet B, Cotten A, Boutry N, Flipo RM, Duquesnoy B, Chastanet P, Delcambre B. Percutaneous vertebroplasty in the treatment of osteoporotic vertebral compression fractures: an open prospective study. J Rheum 1999;26:2222-8

11. Yeom JS, Kim WJ, Choy WS, Lee CK, Chang BS, Kang JW. Leakage of cement in percutaneous transpedicular vertebroplasty for painful osteoporotic compression fractures. J Bone Joint Surg (Br) 2003;85:83-9

12. Choe du H, Marom EM, Ahrar K, Truong MT, Madewell JE. Pulmonary embolism of polymethyl methacrylate during percutaneous Vertebroplasty and kyphoplasty. Am .J Roentgenol 2004;183:1097-102

13. Groen RJ, du Toit DF, Phillips FM, Hoogland PV, Kuizenga K, Coppes MH, et al. Anatomical and pathological considerations in percutaneous vertebroplasty and kyphoplasty: a reappraisal of the vertebral venous system. Spine 2004;29:1465-71

14. Aebli N, Krebs .J, Davis G, Walton M, Williams M.J, Theis .JC. Fat embolism and acute hypotension during vertebroplasty - an experimental study in sheep. Spine $2002 ; 27: 460-6$

15. Berlemann U, Ferguson S.J, Nolte LP, Heini PF. Adjacent vertebral failure following vertebroplasty: a biomechanical investigation. J Bone Joint Surg (Br) 2002;84:74852

16. Heini PF, Orler R. [Vertebroplasty in severe osteoporosis. Technique and experience with multi-segment injection]. Orthopade 2004;33:22-30

17. Phillips FM, Todd WF, Lieberman I, Campbell-Hupp M. An in vivo comparison of the potential for extravertebral cement leak after vertebroplasty and kyphoplasty. Spine $2002 ; 27: 2173-9$

18. Hillmeier J, Meeder PJ, Noldge G, Kock HJ, Da Fonseca K, Kasperk HC. [Balloon kyphoplasty of vertebral compression fractures with a new calcium phosphate cement]. Orthopade 2004;33: 31-9

19. Berlemann U, Franz T, Orler R, Heini PF. Kyphoplasty for treatment of osteoporotic vertebral fractures: a prospective non-randomized study. Eur Spine J 2004;13:496-501

20. Garfin SR, Yuan HA, Reiley MA. Kyphoplasty and vertebroplasty for the treatment of painful osteoporotic compression fractures. Spine 2001;26:1511-5

21. Lieberman IH, Dudeney S, Reinhardt MK, Bell G. Initial outcome and efficacy of „kyphoplasty" in the treatment of painful vertebral compression fractures. Spine 2001;26: $1631-8$

22. Kasperk C, Hillmeier J, Noldge G, Grafe IA, DaFonseca K, Raupp D, et al. Treatment of painful vertebral factures by kyphoplasty in patients with primary osteoporosis: A prospective nonrandomized controlled study. .J Bone Min Res 2005;20:604-12

23. Heini PF, Orler R. Kyphoplasty of osteoporotic vertebral fractures. Eur Spine J 2004;13:184-92

24. Ledlie JT, Renfro M. Balloon kyphoplasty: one-year outcomes in vertebral body height restoration, chronic pain, and activity levels. J Neurosurg (Spine 1) $2003 ; 98: 36-42$

25. Ross PD. Clinical consequence of vertebral fractures. Am J Med 1997;103: $30 \mathrm{~S}-42 \mathrm{~S}$. 
26. Fribourg D, Tang C, Sra P, Delamarter R, Bae H. Incidence of subsequent vertebral fracture after kyphoplasty. Spine 2004;29:2270-6

27. Watts NB, Harris ST, Genant HK. Treatment of painful osteoporotic vertebral fractures with percutaneous vertebroplasty or kyphoplasty. Osteoporos Int 2001;12:429-37

28. Galibert P, Deramond H, Rosat P, Le Gars D. Note préliminaire sur le traitement des angiomes vertébraux par vertébroplastie acrilique percutanée. Neurochirurgie $1987 ; 33: 166-8$

29. Wetzel SG, Martin JB, Somon T, Wilhelm K, Rufenacht DA. Painful osteolytic metastasis of the atlas: treatment with percutaneous vertebroplasty. Spine $2002 ; 27: \mathrm{E} 493-5$

30. Cotten A, Dewatre F, Cortet B, Assaker R, Leblond D, Duquesnoy B, et al. Percutaneous vertebroplasty for osteolytic metastases and myeloma: effects of the percentage of filling and the leakage of methyl methacrylate at clinical follow-up. Radiology 1996;200:525-30

31. Dudeney S, Lieberman IH, Reinhardt MK, Hussein M. Kyphoplasty in the treatment of osteolytic compression fractures as a result of multiple myeloma. J Clin Oncol 2002;20:2382-7

32. Murphy K.J, Deramond H. Percutaneous vertebroplasty in benign and malignant disease. Neuroimaging Clin N Am 2000;10:535-45

33. Rhyne A 3rd, Banit D, Laxer E, Odum S, Nussman D. Kyphoplasty: Report of 82 thoracolumbar osteoporotic vertebral fractures. J Orthop Trauma 2004;18:2949

34. Steinmann J, Tingey CT, Cruz G, Dai Q. Biomechanical comparison of unipedicular versus bipedicular kyphoplasty. Spine 2005;30:201-5.

35. Rami PM, McGraw JK, Heatwole EV, Boorstein JM. Percutaneous vertebroplasty in the treatment of vertebral body compression fracture secondary to osteogenesis imperfecta. Skeletal Radiol 2002;31:162-5

36. Boszczyk B, Bierschneider M, Potulski M, Robert B, Vastmans .J, .Jaksche H. Erweitertes Anwendungsspektrum der Kyphoplastie zur Stabilisierung der osteoporotischen Wirbelfraktur. Unfallchirurg 2002;105:952-7

37. Chung SK, Lee SH, Kim DY, Lee HY. Treatment of lower lumbar radiculopathy caused by osteoporotic compression fracture: the role of vertebroplasty. J Spinal Disord Tech 2002;15:461-8

38. Masala S, Tropepi D, Fiori R, Semprini R, Martorana A, Massari F, et al. Kyphoplasty:
A new opportunity for rehabilitation of neurologic disabilities. Am .J Phys Med Rehabil 2004;83:810-2

39. Cooper C, Atkinson EJ, Jacobsen S.J, O'Fallon WM, Melton LJ 3rd. Populationbased study of survival after osteoporotic fractures. Am J Epidemiology $1993 ; 137: 1001-5$

40. Kado DM, Browner WS, Palermo L, Nevitt MC, Genant HK, Cummings SR. Vertebral fractures and mortality in older women. Arch Intern Med 1999;159:121520

41. Schlaich C, Minne HW, Bruckner T, Wagner G, Gebest HJ, Grunze M, et al. Reduced pulmonary function in patients with spinal osteoporotic fractures. Osteoporos Int $1998 ; 8: 261-7$

42. Komp M, Ruetten S, Godolias G. Minimal-invasive Therapie der funktionell instabilen osteoporotsichen Wirbelkörperfraktur mittels Kyphoplastie; Prospektive Vergleichsstudie von 19 operierten und 17 konservativ behandelten Patienten. .J Miner Stoffwechs 2004:11:13-5

43. Belkoff SM, Mathis JM, Jasper LE, Deramond H. The biomechanies of vertebroplasty. The effect of cement volume on biomechanical behavior. Spine 2001;26:1537-41

44. Deramond H, Wright NT, Belkoff SM. Temperature elevation caused by bone cement polymerization during vertebroplasty. Bone 1999;25:17S-21S

45. Siddall PJ, Cousins MJ. Spinal pain mechanisms. Spine 1997;22:98-104

46. Hillmeier J, Grafe I, Da Fonseca K, Meeder PJ, Noldge G, Libicher M, et al. Die Wertigkeit der Ballonkyphoplastie bei der osteoporotischen Fraktur. Orthopade 2004;33:893-904

47. Cotten A, Dewatre F, Cortet B, Assaker R, Leblond D, Duquesnoy B, et al. Percutanous vertebroplasty for osteolytic metastases and myeloma: effects of the percentage of lesion filling and the leakage of methyl methylacrylate at clinical followup. Radiology 1996;200:525-30

48. Nakano M, Hirano N, Matsuura K, Watanabe H, Kitagawa H, Ishihara H, et al. Percutaneous transpedicular vertebroplasty with calcium phosphate cement in the treatment of osteoporotic vertebral compression and burst fractures. .J Neurosurg 2002;97:287-93

49. Ohnsorge JA, Siebert CH, Schkommodau E, Mahnken AH, Prescher A, Weisskopf M. [Minimally-invasive computer-assisted fluoroscopic navigation for kyphoplasty.] Z Orthop 2005;143:195-204 